Cahiers $d u$ MONDE RUSSE

\section{Cahiers du monde russe}

Russie - Empire russe - Union soviétique et États indépendants

52/2-3 | 2011

L'URSS et la Seconde Guerre mondiale

\title{
Allocution d'ouverture
}

\section{Marc Ferro}

\section{OpenEdition \\ Journals}

Édition électronique

URL : https://journals.openedition.org/monderusse/9350

DOI : $10.4000 /$ monderusse. 9350

ISSN : $1777-5388$

Éditeur

Éditions de l'EHESS

Édition imprimée

Date de publication : 15 novembre 2011

Pagination : 499-504

ISBN : 978-2-7132-2352-5

ISSN : $1252-6576$

\section{Référence électronique}

Marc Ferro, «Allocution d'ouverture », Cahiers du monde russe [En ligne], 52/2-3 | 2011, mis en ligne le 12 septembre 2014, consulté le 04 septembre 2022. URL : http://journals.openedition.org/ monderusse/9350; DOI : https://doi.org/10.4000/monderusse.9350 
Marc Ferro, éminent historien, spécialiste de l'URSS et des guerres mondiales, avait fait l'honneur d'ouvrir le colloque dont nous publions, pour partie, les actes dans ce présent numéro spécial. C'est en historien mais aussi en témoin de cette guerre qu'il a livré en avant-propos quelques réflexions sur le regard que certains des belligérants ont alors porté sur l'URSS, avant de remémorer un écho personnel de la perception des Russes ${ }^{1}$.

\section{Allocution d'ouverture}

Mes chers collègues, mes chers amis,

$[\ldots]$, après lecture de ce programme si novateur $[\ldots]$ je me suis demandé où nicher mon intervention d'ouverture.

J'ai pensé que le plus simple serait peut-être d'introduire ce colloque par le rappel du regard que les autres belligérants ont porté sur l'URSS en guerre. Faute de temps, j'évoquerai ici seulement le cas de l'Allemagne, de l'Italie et de l'Extrême-Orient.

\section{L'Allemagne}

Premier trait : le regard des Allemands porte d'abord sur l'évaluation des forces de l'Union soviétique.

Dès 1939, un rapport militaire pose que « l'armée soviétique est incapable de se battre, ses soldats sont mal armés, mal entraînés ».

Pendant l'hiver 1939-1940, « en Finlande, ils sont coincés, l'Armée rouge semble vraiment avoir peu de valeur ».

À une cérémonie commémorant le pacte germano-soviétique, on voit aux Deutsche Wochenshau le regard méprisant et goguenard du général allemand devant des canons de 76 russes tirés par de beaux chevaux blancs harnachés. "L'armée soviétique est une plaisanterie », dit Hitler à Dragomirov, ambassadeur de Bulgarie. « C'est zéro », dit-il et répète-il. « Les Russes sont une race de lapins ». Il réitère : «Stalin est comme un lapin devant le serpent », dit-il lorsque celui-ci multiplie les concessions pour prévenir une attaque allemande, au printemps 1941.

1. Marc Ferro vient de publier :1917. Les hommes et la révolution : témoignages et documents, P. : Omnibus, 2011, 1115 p. Ils étaient sept hommes en guerre (1918-1945) : histoire parallèle, P. : Éditions Robert Laffont, 2007, (Perrin, 2008). 
La guerre commence et après que les Deutsche Wochenshau ont montré la marche triomphale des Allemands, on voit le défilé pitoyable de prisonniers soviétiques déguenillés et avachis, des « sous-hommes » au regard de ces caméras qui sélectionnent les plus pitoyables.

Or, lorsque la boue, puis le froid, bloquent le matériel blindé allemand, un premier signal apparaît : Goebbels et plusieurs généraux s'inquiètent que les soldats n'aient pas de vêtements chauds pour l'hiver... Voilà qui rompt avec la certitude que la guerre serait terminée en quelques semaines...

Deuxième signal : ces soldats et officiers tétanisés devant les premiers chars T-34 : «Ils font flamber les nôtres comme des boîtes d'allumettes », commente le général Reinhardt.

Troisième signal, l'impossibilité de bombarder Moscou de jour tellement la défense anti-aérienne soviétique est efficace.

Quatrième signal : une colère d'Hitler découvrant plus de 2000 kilomètres de voies ferrées russes, alors qu'elles ne figurent pas sur les cartes. Plus : les Allemands savent qui habite dans chacun des beaux immeubles de la capitale russe, mais découvrent des usines vidées de leur matériel dans des bourgades mal identifiées. Et voilà que Goering manifeste son irritation début 1943 : «Mais où donc les bolcheviks prennent-ils leurs réserves ? Et Hitler de lui répondre « avec les bolcheviks on ne peut jamais savoir ». Bien sûr les Deutsche Wochenshau ne laissent pas suinter la perplexité qui commence à envahir les dirigeants allemands, à part l'image d'officiers effarés devant un T-34 endommagé et les effets de la boue ou du froid.

L'héroïsme des soldats et le civisme du peuple allemand, prompt à donner couvertures et vêtements, sont tellement bien mis en valeur que la force des Soviets, que les chefs perçoivent, n'est pas encore sensible à ceux de l'arrière. L'Allemagne est le seul pays où les salles spécialisées dans les actualités ont toujours plus de spectateurs enthousiastes que celles où on montre du cinéma-cinéma...

Deuxième trait : après Stalingrad, les dirigeants allemands modifient leur manière de juger le régime soviétique, jusque-là totalement négative. Le point d'ancrage en est l'évaluation portée sur leur propre commandement. « Ce ne sont pas des chiens-dogues », disait déjà Hitler en 1940 ; mais surtout, dès 1942, il ne les juge plus fiables avec cette idée centrale qui revient une bonne dizaine de fois avant Stalingrad, et plus encore après la sécession du maréchal Paulus : « en 1918, l'arrière a trahi l'armée, et aujourd'hui, c'est l'armée qui trahit l'arrière », l'armée, c'est-à-dire le commandement.

«Sont forts les États qui ont une conception de l'univers, l'adversaire en a une aussi, même si elle est erronée » explique Hitler, et de commenter : « Nous faisions fausse route quand nous estimions, à propos du cas Tuhačevskij, que Stalin serait l'auteur de la démolition de l'Armée rouge. C'est le contraire qui s'est avéré; il a expulsé tous les milieux d'opposants hors de l'Armée rouge et est parvenu à l'élimination de tout courant défaitiste en son sein. »

La nomination de commissaires politiques à la direction de l'armée a été un coup de génie, et il a éliminé les derniers éléments faibles à la direction de l'armée, 
mettant à leur place des hommes venus du parti. Bientôt Hitler l'imitera, Himmler sera, à son tour, à la tête de bien des forces militaires allemandes.

«Alors que chez nous l'opposition récrimine, empoisonne la vie, Stalin a façonné le peuple de façon homogène par l'éducation et par le knout », ajoute le Führer (8 mai 1943).

«Et puis il a "katynisé" l'aristocratie polonaise en abandonnant son sort à Varsovie... C'était le but de l'opération.»

«Stalin doit bien rire quand il entend des Anglais croire qu'on le transformera de révolutionnaire en homme d'État. »

Troisième trait : «Oui, le Führer a un immense respect pour Stalin qu'il considère comme un véritable génie du peuple asiatique » (Goebbels).

«Pour le moment conclure avec lui est du domaine de l'utopie, car nous avons besoin de 1'Ukraine... L'Asie s'effondrera d'un coup, même si sous le commandement de Stalin ce sera plus dur que dans le passé... Pourtant une paix avec un dictateur, on ne peut pas s'y fier.»

«Avec 1'Angleterre, elle, il lui faudra vingt ans pour qu'un parlement l'autorise à nouveau à entrer en guerre, il suffira de l'avoir rassasiée en Méditerranée. »

« Il faudrait même souhaiter une rapide avancée soviétique qui alarmera les Américains et hâtera le retournement qui est inéluctable, et nous nous retrouverons ensemble à combattre l'URSS. »

Ces deux thèmes étant dix fois tournés et retournés.

\section{Mussolini voit les choses autrement...}

À l'apogée de l'alliance avec Hitler et bien qu'il n'ait pas été prévenu de la signature du pacte germano-soviétique, Mussolini est appâté par la faiblesse que manifeste la Russie en Finlande.

En janvier 1940, il dit au Führer : «C'est le jour où nous aurons détruit le bolchevisme que nous pourrons avoir foi en nos deux révolutions ».

À la veille de l'attaque allemande de juin 1941, il dit à Clara Petacci, sa maîtresse en titre : « Hitler commet une erreur, il se bat sur trop de fronts... La guerre sera très longue. Notre appui sera enfin plus visible. Alors nous pourrons vraiment demander un espace vital pour l'Italie. »

Plus tard, juste avant le débarquement en Sicile, le 9 juillet 1943, il conseille à Hitler de signer une paix séparée avec la Russie, combinée avec une attaque sur Gibraltar. Plus tard encore, il réitérera cet avis.

Mais le plus intéressant est bien la confession que Mussolini fait auprès de Victor Barthélémy, 1'envoyé de Doriot alors à Sigmaringen au printemps 1945 quelque temps avant sa mort. Ce texte, on peut le dire, est un inédit car aucun historien du fascisme italien n'en a jamais pris connaissance. « Pourquoi n'avez-vous pas agi comme les communistes qui ont créé le Komintern ?», lui demande V. Barthélémy. «Sans doute l'aurait-il fallu », répond Mussolini. 
Mais il y avait bien des difficultés pour créer un tel projet. I1 y a une grande différence entre communisme et fascisme. Le communisme est basé sur deux idées fondamentales : la lutte des classes, une évidence, l'internationalisme, une nécessité. Le fascisme, lui, répudie la lutte des classes en tant que moteur de l'histoire et considère le fait national comme une évidence et une nécessité du développement des peuples, il n'est pas internationaliste.

«Ah, si Hitler m'avait écouté. On aurait fait la paix avec les Russes. Dans cette guerre, ce ne sont pas les Russes qui sont nos ennemis, mais les Anglo-Saxons. » Stalin n'aurait pas demandé mieux. Et la Russie ne représentait plus un danger pour l'Europe après les coups qu'elle avait reçus.

Mais Hitler était obnubilé par la Russie. Les Allemands sont de remarquables soldats et organisateurs, mais ils ne comprennent rien à la politique, car ils partent d'idées préconçues dont ils ne veulent pas démordre. Pour Hitler, l'Angleterre est une sœur de race avec qui on peut s'entendre et la Russie un pays de sauvages, de sous-hommes qu'il faut faire disparaître, et dont le territoire doit devenir une colonie pour les Européens, entendez pour les Allemands.

Sur les deux points, Hitler se trompe.

Les Anglais sont la nation la plus égoïste, la plus féroce de la terre. Et les Russes ne sont pas des sauvages, c'est le bolchevisme qui est une erreur monstrueuse et criminelle. La Russie a produit de grands savants, de grands musiciens, des écrivains de génie. J'ai été le premier à établir des relations avec eux et je ne m'en suis jamais plaint.

Et ailleurs ce jugement : «Stalin est le seul homme qui puisse présenter les mains propres devant le tribunal de l'Histoire. »

\section{Le Japon}

Depuis l'incident de Mandchourie en 1931, le Mikado avait recommandé aux chefs de l'armée de terre de ne pas dépasser la Grande Muraille pour ne pas susciter un conflit avec l'URSS. L'orientation anti-communiste et anti-soviétique de sa politique était pourtant nette et elle le demeura jusqu'à l'extension de l'invasion de la Chine et après la constitution d'un Mandchoukouo vassal.

L'adhésion au pacte anti-komintern illustrait bien l'engagement japonais dans le camp anti-soviétique.

Le pacte Hitler-Stalin apparut au Mikado une trahison à laquelle s'ajouta une deuxième humiliation, la défaite des forces japonaises devant les Russes à Nomonham (sept. 1939), bataille demeurée inaperçue en Occident.

Lorsque l'Allemagne va entrer en guerre contre l'URSS, la mission Matsuoka permet au Mikado de venger l'affront en signant avec Stalin un pacte de non-agression.

À cette date, au Japon, seul le premier ministre Konoye, bientôt remercié, prévoit que les Allemands n'entreront jamais à Moscou.

Pourtant, alors que la Marine voudrait profiter de la défaite de la France et de l'affaiblissement des Anglo-Hollandais pour satisfaire les ambitions grandissantes 
du Japon en Indonésie et en Indochine et ne plus demeurer attaché à l'ancienne politique, sorte de doctrine de Monroe asiatique réservée aux confins de l'archipel nippon, les victoires allemandes de l'été 1941 attisent les appétits des militaires, avides d'une revanche sur Nomonham. Renaît l'idée d'un gage en Sibérie, en accord avec les Allemands : «Le Japon ne veut pas être en retard d'un autobus ».

Envisageant le partage du transsibérien, militaires allemands et japonais se donnent rendez-vous à Omsk. Les Allemands étant bloqués devant Moscou, la Marine fait valoir qu'elle a le temps de vaincre les États-Unis avant qu'ils soient militairement prêts et de pouvoir ainsi, ensuite, se retourner contre l'URSS quand les Allemands auront repris leur élan.

C'est exactement le raisonnement qu'avait tenu Hitler, après l'échec de la bataille d'Angleterre, comptant vaincre l'URSS en deux temps trois mouvements, dès 1940 même, pour pouvoir se retourner ensuite contre 1'Angleterre, avec la Russie qui lui apporterait ses réserves, comme les États-Unis apportaient les leurs à la Grande-Bretagne.

Et ce fut Pearl Harbour avec cette instruction impériale que les avions japonais devaient éviter de trop se rapprocher des côtes de la Sibérie, en passant par le nord.

Trois ans plus tard, après la bataille du Pacifique et la perte d'Okinawa, les Japonais appellent les Russes à l'aide pour qu'ils leur livrent avions et pétrole. En échange, le Japon offre toutes les Kouriles et Sakhaline avec.

«Le Mikado a confiance en Stalin », énonce le rapport Kido, principal conseiller de l'empereur à la veille de la conférence de Potsdam. Il fait même appel à son intercession.

Trop tard, l'URSS a promis aux Alliés d'intervenir ; elle traîne et intervient seulement le 9 août $1945 \ldots$ Et la bombe A a éclaté.

\section{Mao Tsé-Tung}

La vision que les communistes chinois ont de Stalin et de l'URSS ne cesse de se détériorer.

En 1927-1928, Stalin abandonne les communistes à la vindicte de Chang Kaï-chek. Ses raisons : ne pas donner aux impérialistes une nouvelle occasion d'intervenir comme ils l'ont déjà fait en 1919, ce qui indirectement menacerait l'URSS...

La méfiance envers les communistes se perpétue pour autant que Mao rompt avec le dogme marxiste-léniniste en s'appuyant désormais bien plus sur la paysannerie que sur la classe ouvrière. Mao sait que Stalin a dit à Harriman, ambassadeur des États-Unis, et répété : «Mao est un bon patriote, mais un ersatz de communiste ».

Entretemps, nouvel affront : quand, en 1936 à Sian, les forces de Mao font Chang Kaï-chek prisonnier, c'est sur l'injonction de Stalin que Mao, en fureur, doit le libérer. Stalin envoie des armes à Chang pour qu'il se batte contre les Japonais, celui-ci les emploie contre Mao à qui « Stalin n'envoie que des revolvers » (sic). 
Quand Mao doit signer une trêve avec Chang sous la pression de Stalin, Mao répond : «Nous ne sommes pas une coquille pourrie comme Chang; aucune nation n'a besoin de nous soutenir », phrase qui, dans son contexte, vise l'URSS.

Derniers affronts : le 9 août 1945, l'URSS déclare la guerre au Japon. Aussitôt Chang et Mao, simultanément invitent les Japonais à ne se rendre qu'à eux. Mais le 15 août, Molotov et Chang signent un traité d'alliance. Et lorsque Mao se rapproche des Américains pour aider à la reddition des Japonais, Moscou fait savoir à Peng Zen, adjoint de Mao : «si vos troupes ne quittent pas les grandes villes, nous utiliserons des tanks pour vous en déloger ». Et Peng Zen de commenter : «L'armée d'un parti communiste utiliserait des tanks pour déloger l'armée d'un autre parti communiste, on n'avait jamais vu cela. »

Entretemps, à Yalta, Roosevelt avait cédé la Mongolie extérieure à l'URSS plus un certain nombre d'avantages en Chine, avantages que 1'URSS avait d'ailleurs abandonnés en 1924. «En avez-vous le droit ? , avait demandé l'ambassadeur Hurley à Roosevelt qui n'avait pas ces scrupules. «Allons, vous avez besoin de nous, pas nous de vous », dit Stalin, qui n'en avait pas non plus, au fils de Chang qui protestait... « Pourquoi faire tant d'histoire sur la Mongolie?»

\section{Et les Français?}

Je n'ai sur eux qu'un seul témoignage, au moins est-il authentique...

C'est celui de mon cousin Henri, prisonnier en Allemagne de 1940 à 1945, et libéré par les Russes, près de Torgau où il était interné.

De retour à Paris, on le fête, chez lui, avec sa femme Fernande et sa fille Nicole, l'oncle Georges, la famille.

Le champagne est sur la table.

« Tu sais, Marc, me dit-il, ce sont les Rousski qui m’ont libéré... Sympaths... Mais tous des voleurs... Regarde ».

Il me montre son poignet avec sa montre et il remonte sa main droite jusqu'à son épaule : «Ils avaient des montres jusque-là ! Tous des voleurs ! » Il rit.

Nous bavardons encore un peu et je m'apprête à partir. «Attends, Marco, regarde... » Il ouvre alors une armoire emplie d'appareils-photographiques. «Prends-en un, c'est pour toi..., je les ai tous piqués aux Allemands... »

Marc Ferro 